\title{
Opinions of the University Students towards Two Learning Object Modules (LOM) on Globally Harmonized System of Classification and Labeling of Chemicals (GHS) and Chemical Safety
}

\author{
Sarisak Soontornchai \\ School of Health Science, Sukhothai Thammathirat Open University, Nonthaburi, Thailand 11120
}

\begin{abstract}
How to cite this paper: Soontornchai, S. (2018). Opinions of the University Students towards Two Learning Object Modules (LOM) on Globally Harmonized System of Classification and Labeling of Chemicals (GHS) and Chemical Safety. The Educational Review, USA, 2(4), 245-252.

http://dx.doi.org/10.26855/er.2018.04.002
\end{abstract}

Corresponding author: Sarisak Soontornchai, D.Sc., School of Health Science, Sukhothai Thammathirat Open University, Nonthaburi, Thailand 11120.

\begin{abstract}
Most of Thai people, particularly, consumers still have health risk from dangerous chemicals. One of the guidelines to prevent and reduce the risk is to promote awareness on chemical safety among Thai children and adolescents. This target groups are potentially important human resources. Additionally, chemicals are extremely used in various occupations of agriculture, industry, and community enterprises. Therefore, the Office of Food and Drug Administration (FDA), Thailand collaborated with School of Health Science, Sukhothai Thammathirat Open University (STOU) for developing online Learning Object Material (LOM). The objective of this research was to study opinions of the University Students towards 2 LOMs on Globally Harmonized System of Classification and Labeling of Chemicals (GHS) (LOM 1) and Chemical Safety (LOM 2). This research supported by FDA (Thailand) was conducted by compiling and analyzing all needed contents for 2 LOMs from reference resources of relevant documents, GHS manual, and internet in order to develop as learning content. The contents were first designed as 2 storyboards for 2 LOMs on 1) GHS and 2) Chemical Safety. The storyboards were then submitted to International Program on Chemical Safety (IPCS), FDA, Ministry of Public Health for consideration and suggestions. The revised storyboards were further revised and sent to E-Learning Center of STOU for developing LOMs with Adobe Flash cs6 Program. Moreover, the LOMs were resubmitted to IPCS for consideration and suggestions. The LOMs were further revised before practical trying-out on-line with 53 B.Sc. (Occupational Health and Safety) students and 44 M.Sc. (Industrial Environmental Management). The research findings were that most of the students had previous knowledge in LOMs, satisfaction of LOM presentation, understanding, presentation sequence, and making use of LOMs at the high level. These two LOMs has then been displaying on School's and STOU's websites and FDA would coordinate with Inter University Network (UniNet) of the Commission of Higher Education in order to disseminate the LOMs to central and regional universities in Thailand.
\end{abstract}

\section{Keywords}

Learning Object Modules, University Student, Globally Harmonized System of Classification and Labeling of Chemicals, Chemical Safety

\section{Introduction}


The United Nations had developed Globally Harmonized System of Classification and Labeling of Chemicals (GHS) in 2003 due to various chemical management systems. It is crucial to harmonize them within the same standard in chemical classification with regards of physical, health, and environmental hazards. Then, hazard communication should be done to targets groups of workers, transporters, emergency responders, and consumers through labels and safety data sheet (SDS).

Thailand has voluntary accepted GHS and mandatory used in industrial sector with collaboration of relevant offices including Ministry of Industry, Ministry of Agriculture and Co-Operatives, and Ministry of Public Health since 13 March 2012. The main objective was to make hazard communication to the mentioned targets. Most of Thai people, particularly, consumers still have health risk from dangerous chemicals. One of the guidelines to prevent and reduce the risk is to promote awareness on chemical safety among Thai children and adolescents. These target groups are potentially important human resources in order to survive safely in current situation of daily uses of chemicals and chemical-based products. Additionally, chemicals are extremely used in various occupations of agriculture, industry, and community enterprises. Preparedness of coping with environmental pollution or accidents incurred from chemical problems is a significant issue.

The National Strategic Plan on Chemical Management IV (2012-2021) of Thailand pays attention to challenge topic of human development to have knowledge for chemical safety management through educational institutes which are crucial partnership. The Office of Food and Drug Administration (FDA) as the Secretariat of the Plan had been conducting projects of knowledge and life skill development among the youth on chemical safety with collaboration of the Office of Basic Educational Commission in order to develop instruments for learning process in primary and secondary schools.

In order to extent the aforementioned projects, FDA collaborated with School of Health Science, Sukhothai Thammathirat Open University (STOU) for developing Learning Object Material (LOM) on GHS and Chemical Safety for the students in B.Sc.(Occupational Health and Safety) and M.Sc. (Industrial Environmental Management). These students would be officers in industrial sector handling with chemicals Those LOMs would be developing potential for these students in classification and labelling of chemicals based on GHS as well as basic knowledge and skill in chemical safety management.

\section{Objectives}

To study the opinion of the students in B.Sc.(Occupational Health and Safety) and M.Sc. (Industrial Environmental Management) towards Learning Object Modules on GHS and Chemical Safety.

\section{Literature Review}

Globally Harmonized System of Classification and Labeling of Chemicals (GHS) is an international system created by the United Nations. It is designed to replace the various classification and labeling standards used in different countries by using consistent criteria for classification and labeling on a global level. GHS classification system is a complex system comprising 3 hazards of physical, health, and environmental hazards with data obtained from tests, literature, and practical experience. The main elements of the hazard classification criteria GHS (Rev.5, 2013) are summarized below:

Physical hazards include: 1) Explosives; 2) Flammable gas; 3) Flammable aerosols; 4) Oxidizing gases; 5) Gases under pressure; 6) Flammable liquid; 7) Flammable solid; 8) Self-reactive substances; 9) Pyrophoric liquid; 10) Pyrophoric solid; 11) Self-heating substances; 12) Substances which on contact with water emit flammable gases; 13) Oxidizing liquids; 14) Oxidizing solids; 15) Organic peroxides; and 16) Substances corrosive to metal.

Health hazards include: 1) Acute toxicity; 2) Skin corrosion/ irritation; 3) Serious eye damage/eye irritation; 4) 
Respiratory/skin sensitizer; 5) Germ cell mutagenicity; 6) Carcinogenicity; 7) Reproductive toxicity; 8) Specific target organ toxicity (STOT) single exposure; 9) Specific target organ toxicity (STOT repeated exposure; and 10) Aspiration hazard.

Environmental hazards include: 1) Hazardous to the aquatic environment and 2) Hazardous to the ozone layer.

After the substance or mixture has been classified according to GHS criteria, the hazards need to be communicated. The communication methods incorporated in GHS include labels and safety data sheet (SDS). GHS attempts to standardize hazard communication so that the intended target groups (workers, transporters, emergency responders, and consumers) have better understand the hazards of the chemicals while handling. GHS application of the hazard communication elements on the label with pictogram, signal word, and hazard statement should be used. National authorities may choose to specify where information should appear on the label or allow supplier discretion. Pictograms have a black symbol on a white background with a red diamond frame (Figure 1).

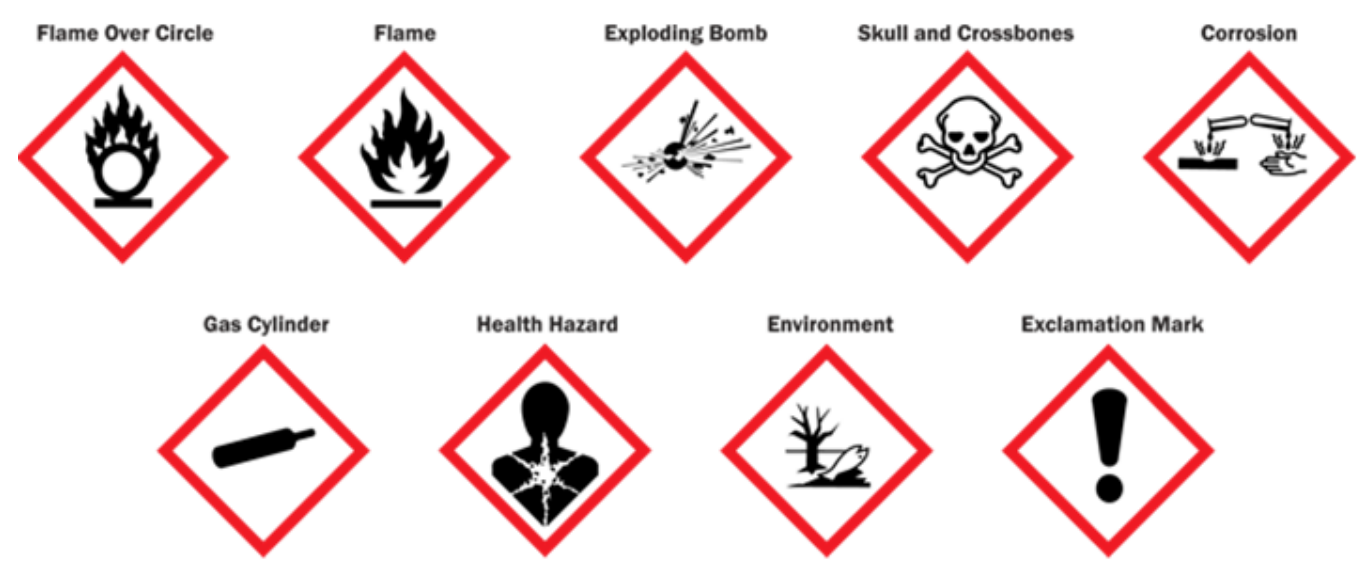

Figure 1. Pictograms.

Signal words ("Danger" or "Warning") are used to emphasize hazards and indicate the relative level of severity of the hazard, assigned to a GHS hazard class and category. Some lower level hazard categories do not use signal words. Only one signal word corresponding to the class of the most severe hazard should be used on a label. Hazard statements are standard phrases assigned to a hazard class and category that describe the nature of the hazard. An appropriate statement for each GHS hazard should be included on the label for products possessing more than one hazard.

The adoption of the GHS is expected to facilitate international trade by increasing consistency between the laws in different countries that currently have different hazard communication requirements. Different countries require different time frames to update current regulations or implement new ones.

\section{Methodology}

\subsection{Development of LOMs}

Contents of LOMs on GHS was searched from various documents, handbooks, and internet including 1) UNITARThailand Workshop Training and Capacity Building for the Implementation of the GHS; 2) Handbook on Hazardous Chemical Management of Department of Industrial Work, Ministry of Industry; 3) http://ipcs.fda.moph.go.thhttp:// ipcs. fda.moph.go.th; and 4) GHS "Purple Book" in Thai version from http://www. npc-se.co.th/pdf/ghs_thai_full.pdf.

The GHS contents were designed as 2 storyboards for 2 LOMs on 1) GHS (Figure 2) and 2) Chemical Safety (Figure 3). 
The storyboards were submitted to International Program on Chemical Safety (IPCS), FDA, Ministry of Public Health for consideration and suggestions. The storyboards were revised and then sent to E-Learning Center of STOU for developing with Adobe Flash cs6. The LOMs were resubmitted to IPCS for consideration and suggestions. The LOMs were then revised before practical trying-out on-line with the students. The content of 2 LOMs was as follows.

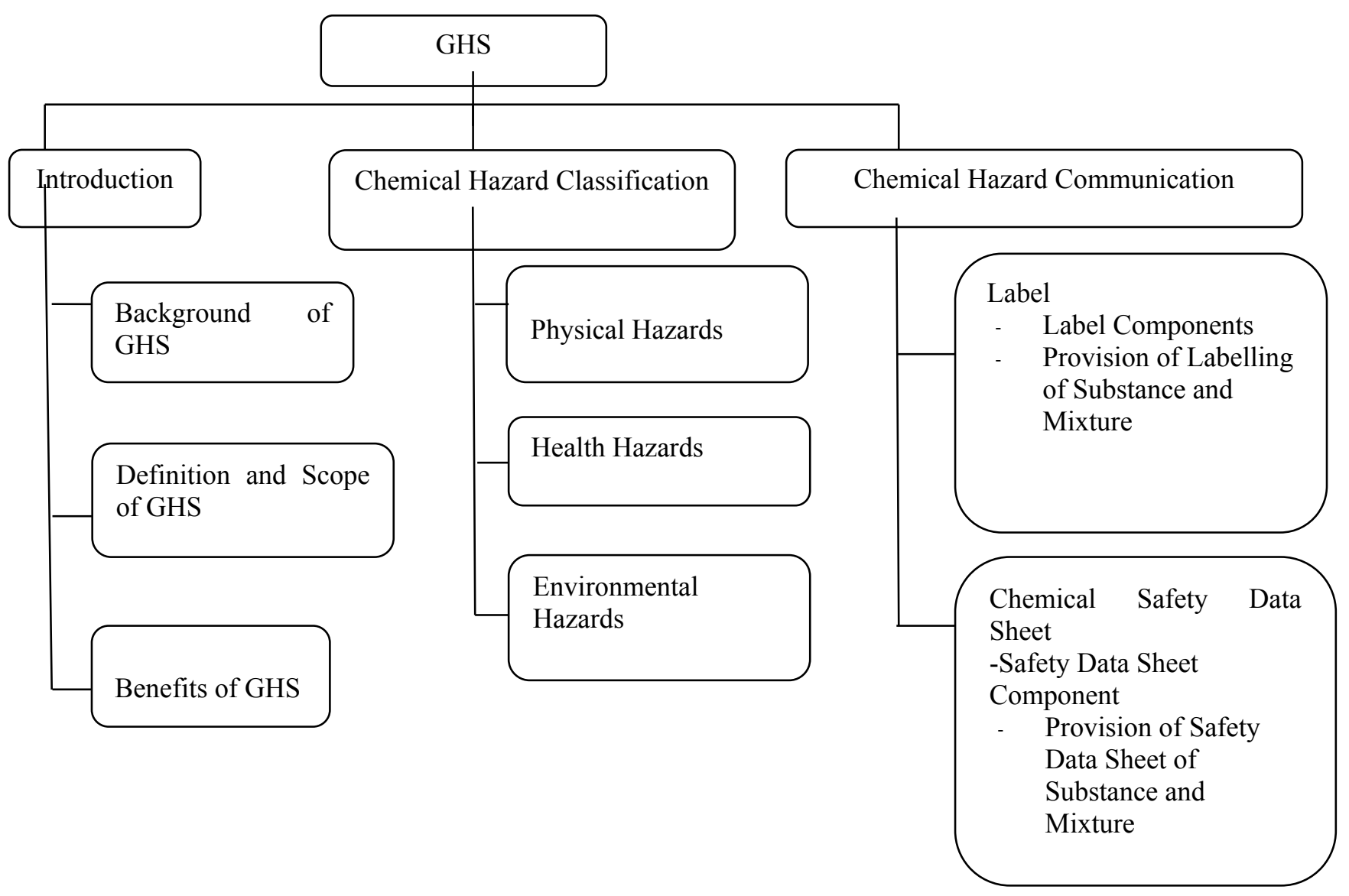

Figure 2. LOM 1 "GHS: Classification and Hazard Communication of Chemicals on Health and Environment".

\subsection{Practical Trying-out of LOMs among University Students}

Two LOMs were uploaded on Website of School of Health Science, STOU with approval of the School in June, 2014. A total of 53 students in B.Sc. (Occupational Health and Safety) and 44 students in M.Sc. (Industrial Environmental Management) tried out these LOMs. Results and suggestions of LOMs' trying-out were evaluated through hsasosar@ hotmail.com by a questionnaire reviewed by IPCS on satisfaction and knowledge acquisition. 


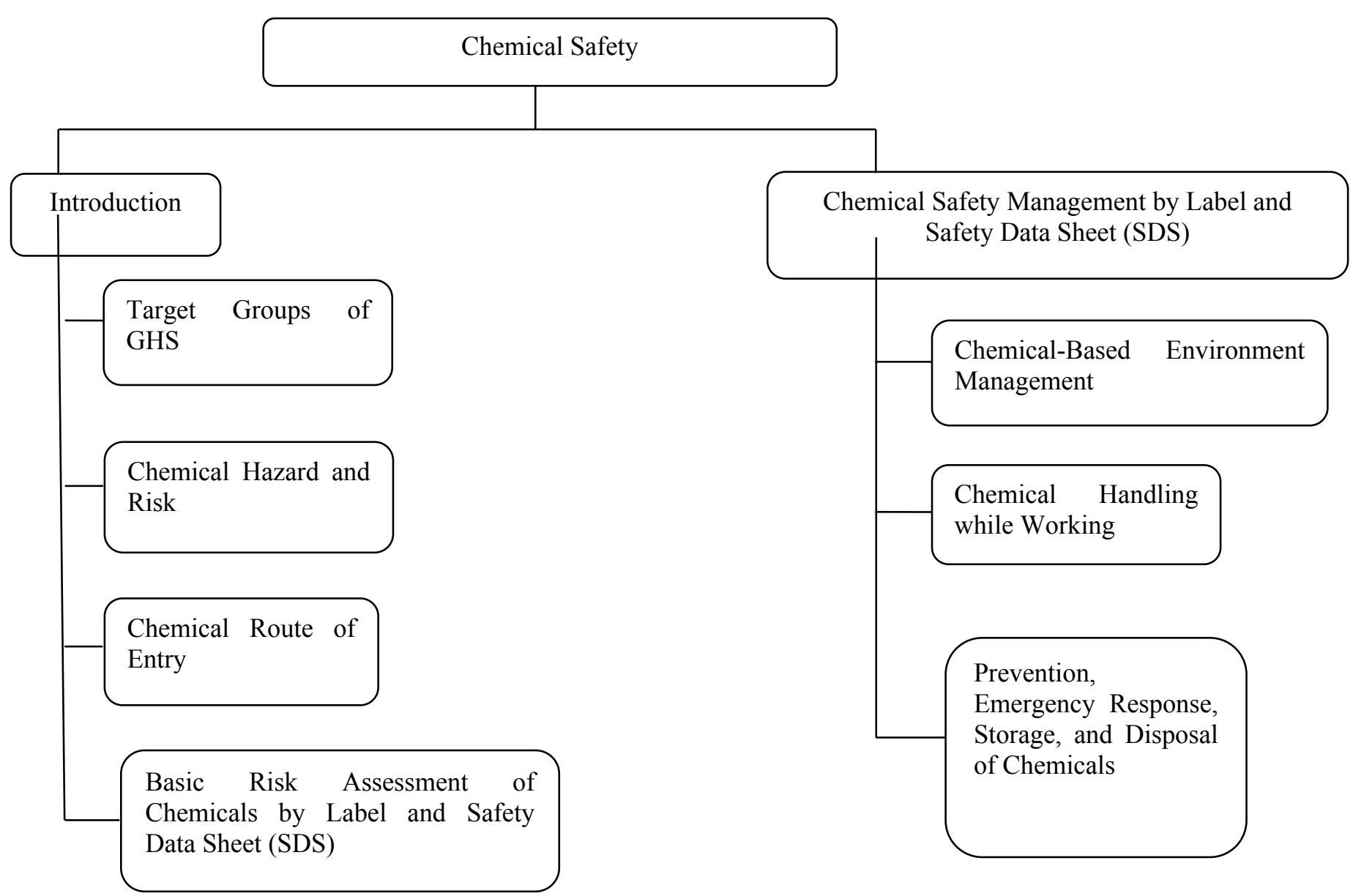

Figure 3. LOM 2 "Chemical Safety".

\section{Results and Discussion}

These 2 LOMs were tried-out among 2 student groups with personal information as shown in Table 1.

LOM 1 (GHS: Classification and Hazard Communication of Chemicals on Health and Environment) was tried-out among 53 University students in B.Sc. (Occupational Health and Safety). Most of them were female (50.9\%), 31-40 years of age (41.5\%), and working as employee (58.5\%). Additionnally, LOM 2 (Chemical Safety) was tried-out among 44 University students in M.Sc. (Industrial Environmental Management). Most of them were female (54.5\%), 21-30 years of age $(38.6 \%)$, and working as employee $(65.9 \%)$.

\subsection{Students' Opinions towards LOM 1 (GHS: Classification and Health and Environment Hazard Communication of Chemicals)}

The opinions of the students towards LOM 1 were shown in Table 2.

The students had previous GHS knowledge on classification and labeling of chemicals (52.8\%) from various sources. They had high satisfaction with LOM 1 presentation (75.5\%), understanding (54.7\%), sequence of presentation (77.4\%), and making use of LOM 1 at the high level (66.0\%) with average use LOM time of $49.15 \mathrm{~min}$. 
Normally, GHS knowledge of School of Health Science, STOU is still included in B.Sc. (Occupational Health and safety) course on Toxicology and Occupational Medicine. Therefore, LOM 1 (GHS: Classification and Health and Environment Hazard Communication of Chemicals) was then developed with the following contents: 1) introduction of GHS; 2) chemical hazard classification of physical, health, and environmental hazards; and 3) chemical hazard communication with label and chemical safety data sheet (SDS). The students had high satisfaction with the contents and presentation due to this topic might be new complicated topic and needed to have additional media. Most of them could utilize this knowledge in their future work as safety officer.

Table 1. Student characteristics participating in trying-out 2 LOMs.

\begin{tabular}{|c|c|c|}
\hline Details & No. of Student & $\%$ \\
\hline \multicolumn{3}{|c|}{$\begin{array}{l}\text { LOM } 1 \text { (GHS : Classification and Hazard Communication of Chemicals on Health and Environment) } \\
\text { Sex }\end{array}$} \\
\hline Male & 26 & 49.1 \\
\hline Female & 27 & 50.9 \\
\hline \multicolumn{3}{|l|}{ Age } \\
\hline 21-30 years & 19 & 35.8 \\
\hline $31-40$ years & 22 & 41.5 \\
\hline $41-50$ years & 10 & 18.9 \\
\hline$>50$ years & 2 & 3.8 \\
\hline \multicolumn{3}{|l|}{ Occupation } \\
\hline Civil Servant & 8 & 15.1 \\
\hline State Enterprise & 1 & 1.9 \\
\hline Self-Employed & 2 & 3.8 \\
\hline Employee & 31 & 58.5 \\
\hline Student & 10 & 18.9 \\
\hline Others & 1 & 1.9 \\
\hline \multicolumn{3}{|l|}{ LOM 2 (Chemical Safety) } \\
\hline \multicolumn{3}{|l|}{ Sex } \\
\hline Male & 20 & 45.5 \\
\hline Female & 24 & 54.5 \\
\hline \multicolumn{3}{|l|}{ Age } \\
\hline 21-30 years & 17 & 38.6 \\
\hline $31-40$ years & 16 & 36.4 \\
\hline $41-50$ years & 9 & 20.5 \\
\hline$>50$ years & 2 & 4.5 \\
\hline \multicolumn{3}{|l|}{ Occupation } \\
\hline Civil Servant & 4 & 9.1 \\
\hline State Enterprise & 0 & 0 \\
\hline Self-Employed & 3 & 6.8 \\
\hline Employee & 29 & 65.9 \\
\hline Student & 8 & 18.2 \\
\hline Others & 0 & 0 \\
\hline
\end{tabular}

\subsection{Students' Opinions towards LOM 2 (Chemical Safety)}

The opinions of the students towards LOM 2 were shown in Table 3.

The students had chemical safety knowledge (79.5\%) from various sources while working. They had high satisfaction with LOM 2 presentation (79.5\%), understanding (68.2\%), sequence of presentation (75.0\%), and making use of LOM 2 $(72.7 \%)$ at the high level with average use time of $49.15 \mathrm{~min}$ as shown in Table 3. 
Table 2. Opinion of the students towards LOM 1 (GHS: Classification and Hazard Communication of Chemicals on Health and Environment).

\begin{tabular}{|c|c|c|}
\hline Details & No. of Student & $\%$ \\
\hline \multicolumn{3}{|c|}{ Previous Knowledge on LOM 1} \\
\hline Yes & 28 & 52.8 \\
\hline No & 25 & 47.2 \\
\hline \multicolumn{3}{|c|}{ Satisfaction towards Presentation on LOM 1} \\
\hline High & 40 & 75.5 \\
\hline Moderate & 13 & 24.5 \\
\hline Low & 0 & 0 \\
\hline \multicolumn{3}{|c|}{ Comprehensibility in Contents on LOM 1} \\
\hline High & 29 & 54.7 \\
\hline Moderate & 20 & 37.7 \\
\hline Low & 3 & 5.7 \\
\hline No reply & 1 & 1.9 \\
\hline \multicolumn{3}{|c|}{ Presentation Sequence of Contents on LOM 1} \\
\hline High & 41 & 77.4 \\
\hline Moderate & 10 & 18.9 \\
\hline Low & 1 & 1.9 \\
\hline No reply & 1 & 1.9 \\
\hline Utilization of Contents on & & \\
\hline High & 35 & 66.0 \\
\hline Moderate & 16 & 30.2 \\
\hline Low & 1 & 1.9 \\
\hline No reply & 1 & 1.9 \\
\hline
\end{tabular}

Table 3. Opinion of the students towards LOM 2 ( Chemical Safety).

\begin{tabular}{|c|c|c|}
\hline Details & No. of Student & $\%$ \\
\hline \multicolumn{3}{|c|}{ Previous Knowledge on LOM 2} \\
\hline Yes & 35 & 79.5 \\
\hline No & 9 & 20.5 \\
\hline \multicolumn{3}{|c|}{ Satisfaction towards Presentation on } \\
\hline \multicolumn{3}{|l|}{ LOM 2} \\
\hline High & 35 & 79.5 \\
\hline Moderate & 9 & 20.5 \\
\hline Low & 0 & 0 \\
\hline \multicolumn{3}{|c|}{ Comprehensibility in Contents on } \\
\hline \multicolumn{3}{|c|}{ LOM 2} \\
\hline High & 30 & 68.2 \\
\hline Moderate & 14 & 31.8 \\
\hline Low & 0 & 0 \\
\hline \multicolumn{3}{|c|}{$\begin{array}{l}\text { Presentation Sequence of Contents } \\
\text { on LOM } 2\end{array}$} \\
\hline High & 33 & 75.0 \\
\hline Moderate & 8 & 18.2 \\
\hline Low & 2 & 4.5 \\
\hline No reply & 1 & 2.3 \\
\hline \multicolumn{3}{|c|}{ Utilization of Contents on LOM 2} \\
\hline \multicolumn{3}{|c|}{ High } \\
\hline Moderate & 32 & 72.7 \\
\hline \multirow[t]{2}{*}{ Low } & 11 & 25.0 \\
\hline & 1 & 2.3 \\
\hline
\end{tabular}

Normally, Chemical safety is still included in M.Sc. (Industrial Environmental Management) course on Systems, Tools and Risk Management for Industrial Environment. Therefore, LOM 2 (Chemical Safety) was then developed with the following contents: 1) introduction; and 2) chemical safety management by label and safety data sheet. This content need 
to be integrated with various knowledge relating to chemical hazard. However, the students had high satisfaction with the contents and presentation of this additional media. Most of them could utilize this knowledge in their chemical safety work.

Apart from the students' opinions for 2 LOMs, the students had some valuable suggestions for revising 2 LOMS in order to make them more friendly use. After LOMs revision according to students' suggestions, National Center for Policy Development on Chemical Safety had arranged a meeting of GHS experts for LOM suggestions and summary at FDA on 31 July, 2014.

These two LOMs had then been displaying on School's and STOU's websites and FDA would co-ordinate with Inter University Network (UniNet) of the Commission of Higher Education in order to disseminate LOMs to central and regional universities in Thailand. These 2 LOMs will help the students working particularly in the companies or factories relating to chemicals to have more confidence while working.

\section{Conclusion}

The students had high satisfaction with these 2 LOMs in terms of LOM presentation, understanding, sequence of presentation, and making use of LOMs at the high level.

\section{Acknowledgement}

I would like to express my sincere thanks to IPCS, FDA (Thailand) for supporting fund and co-ordinate relevant information in the research. The experts would much be appreciated for valuable suggestions in terms of the contents and application of the LOMs. Additionally, thank you for all students participating in practical trying-out the LOMs with suggestions for revising these LOMs to be users friendly and practically. This article had been oral presented in the 29th Annual Conference of the Asian Association of Open Universities (AAOU 2015) organized by Open University Malaysia (OUM) and Asian Association of Open Universities (AAOU) on 30th November-2nd December 2015 at Kuala Lumpur Conventional Centre (KLCC), Kuala Lumpur.

\section{References}

GHS ("Purple Book") Rev.5 (2013). Retrieved from http://www. npc-se.co.th/pdf/ghs_thai_full.pdf.

Manual on Dangerous Chemical Management. Department of Industrial Work.Ministry of Industry.Retrived from http://www.jorpor.com/.

National Center for Policy Development on Chemical Safety. The Office of Food and Drug Administration. Ministry of Public Health. Retrieved from http://ipcs.fda.moph.go.thhttp:// ipcs. fda.moph.go.th.

Soontornchai, S. (2010). Globally Harmonized System of Classification and Labeling of Chemicals (GHS) in Systems, Tools and Risk Management for Industrial Environment . Unit 5 .School of Health Sciene.Nonthburi: SukhothaiThammathirat Open University Press.

Training on GHS and Development of Thailand Chemical Management towards Internationalization.UNITAR-Thailand Workshop Training and Capacity building for the Implementation of the GHS. December, 2012. 